Bangladesh J. Bot. 49(3): 499-505, 2020 (September)

\title{
DISTRIBUTION OF NUTRIENTS IN CAMELLIA OLEIFERA ABEL. AND THEIR CORRELATION WITH SOIL NUTRIENTS OVER THE PERIOD OF FRUIT MATURATION
}

\author{
Jia Luo ${ }^{1,2}$, Xiaoling Zhou ${ }^{1,2 *}$, Yuxin Tian ${ }^{1,2}$, Yongzhong Chen $^{1}$, \\ AND LONGSHEN CheN ${ }^{1}$ \\ National Engineering Research Center for Oil-tea Camellia, Hunan Academy of Forestry, \\ Changsha, Hunan,410004, China
}

Keywords: Nutrient distribution, Camellia oleifera, Maturation, Soil nutrients, Correlation

\begin{abstract}
In order to provide the scientific basis for Camellia oleifera nutrient diagnosis and fertilizer formulation, the correlation between soil nutrients and nutrient elements in different organs of Camellia oleifera was studied in ten-year-old Camellia oleifera in Changning city. The results showed that among the nutrient elements, the content of $\mathrm{N}$ and $\mathrm{P}$ were the highest and lowest in various organs, respectively. Correspondingly, the highest content of macro-element in the soil was Ca. Besides, there were diverse relations among nutrients in soil and those in different organs of Camellia oleifera. Soil nutrients were most closely associated with that of stem, so was soil $\mathrm{N}, \mathrm{Zn}, \mathrm{Mn}, \mathrm{Pb}$ and $\mathrm{K}$ with the plant nutrients. In addition, soil exchangeable $\mathrm{Mn}$ content was positively correlated with nutrients of different organs. Moreover, soil $\mathrm{N}$ showed highly significant correlation with $\mathrm{N}$ content in stem while soil Cd content was negatively correlated with Cd content of all organs. Thus, there prevails a complex interaction of nutrient elements in the soil and exists a synergy or/and antagonism effect among of elements in plants. Consequently, the understanding of effect of interaction between different elements might provide better idea for achieving the precise fertilization, which could further reduce costs and increase production.
\end{abstract}

\section{Introduction}

The Camellia oleifera, known as "eastern olive oil" in China, almost met the international nutritional standards of "omega meals" (Li et al. 2011). Cultivation of the Camellia oleifera properly is of great importance, which is not only to alleviate the contradiction between oil supply and demand, but also improve the structure of the edible oil further to increase the profit of agricultural and forestry in China (Chen et al. 2017). Recently, the Camellia oleifera industry has been facing two major problems, namely poor economic performance and low production per unit area, of which soil nutrient supplement and the rational fertilization are the key factors influencing the oil yield (Gao et al. 2015 and 2017).

Recently, many researchers (He et al. 1996, Song et al. 2014, Liu et al. 2018) have indicated that the nutrient elements have a significant impact on growth and development of Camellia oleifera. He et al. (1996) found that the content of N, P and K varies with growth ages and growing sites, which mainly existed in fruit, flower and leaf. Ding et al. (2012) analyzed the nutrient characteristic of Camellia oleifera planting soil in Guangdong province, and found that the content of biomass was lower as the age increased, except the element of N, P and K indicating that the contents of nitrogen, phosphorus, and potassium in soil were the restricting factor. Besides, Yao et al. (2017) preliminarily studied the correlation of Camellia oleifera yield and soil nutrient and reported that there would be a complex interaction between the soil nutrient resulting the effect of synergy or/and antagonism among of elements in plants. At present, few literatures were published on the correlation between the nutrient of Camellia oleifera tree with soil.

\footnotetext{
*Author for correspondence: <zxling36@163.net>. ${ }^{1}$ Hunan Academy of Forestry, Changsha, Hunan, 410004,
} China; ${ }^{2}$ Hunan Cili Forest Ecosystem State Research Station, Cili-427200, China. 
Accordingly, this study was undertaken to focus on the correlation between the nutrient features of Camellia oleifera tree and soil during maturity stage of plant growth. Thereafter, the coupling relationship of them was built and analyzed.

\section{Materials and Methods}

The experimental plot is located in Changning city, Hunan province (north latitude $26^{\circ} 07^{\prime}$ $26^{\circ} 36^{\prime}$, longitude $112^{\circ} 07^{\prime} \sim 112^{\circ} 41^{\prime}$ ). This place has subtropical monsoon humid climate where the annual average temperature and rainfall are $18.1^{\circ} \mathrm{C}$ and $1436 \mathrm{~mm}$, respectively. The landscape mainly includes mountains, posts and plains, which are dominated by red soil. In addition, the layer of soil is more than $80 \mathrm{~cm}$.

The improved varieties of Camellia oleifera were cultivated in Guanling town, Changning city (E112 $\left.12^{\prime} 29^{\prime \prime}, \mathrm{N} 26^{\circ} 24^{\prime} 58^{\prime \prime}\right)$. The tree-age of Camellia oleifera is 10a, and there are 1500 trees per hectare, in which the survival rate is above $95 \%$. Furthermore, the average height of Camellia oleifera forest is $2.1 \mathrm{~m}$, and the average size of canopy is $2.5 \mathrm{~m} \times 3 \mathrm{~m}$.

The mature forest was selected as the typical representative, and the stood forest for investigation. The standing forest was divided into three permanent sample plots with the same plant conditions and crown density, in which the cultivated area of sample was provided for $20 \mathrm{~m} \times 20 \mathrm{~m}$ and the PVC pipe was respectively set up in four corners of the samples.

Two types of samples were prepared. Five mature trees were selected for each sample plot as the standard specimen. Thereafter, the third-fifth pieces of mature leaf with consistent growth all around were collected; the fruit and flower were collected from around the forest canopies of same stage of growth. The $500 \mathrm{~g}$ of fresh sample, including leaf, flower, fruit, roots, branches, and stem, was air-dried to constant weight at $65^{\circ} \mathrm{C}$, and then ground to $0.25 \mathrm{~mm}$ for the mensuration of nutrient element.

The soil samples were collected from various permanent sample plots within radius of one meter in terms of three different soil depths, including $0-20 \mathrm{~cm}, 20-40 \mathrm{~cm}$ and $40-60 \mathrm{~cm}$. Thereafter, five soil samples were randomly selected, mixed and air-dried to constant weight at $65^{\circ} \mathrm{C}$, and then ground to $<2 \mathrm{~mm}$ for the mensuration of nutrient element. Each sample was triplicated for soil and plant and the average value was reported.

Content of nitrogen in Camellia oleifera tree was determined by Kjeldahl distillation (Green and Jesse 1931). The other elements of Camellia oleifera tree, including $\mathrm{P}, \mathrm{K}, \mathrm{Ca}, \mathrm{Mg}, \mathrm{Cu}, \mathrm{Fe}, \mathrm{Zn}$, $\mathrm{Mn}, \mathrm{Cd}$ and Pd were determined by vanadium-molybdenum colorimetric method (Tomskii et al. 2017). The content of nitrogen and phosphorus in soil was measured by semi-micro Kjeldahl distillation (Jenden et al. 2002) and Molybdenumly anticolorimetry (Hasegawa et al. 2017), respectively.

\section{Results and Discussion}

The results of macroelements in various organs of Camellia oleifera tree indicated that the content of $\mathrm{N}$ and $\mathrm{P}$ in various organs were the highest and lowest respectively among all the elements (Fig. 1). Many recent reports have shown that the leaf was often regarded in an indicative sample during the processing of nutrient diagnosis. The basis of physiological activities within the tree mainly depends on the conversion function of leaf surface which transformed the solar energy into the organic matter (Pauli et al. 2017). The content of $\mathrm{N}$ in leaves was the highest (16.8 g/kg) when compared with other organs (Fig. 1). Furthermore, the total of macroelement could be very high in the leaf and branch, and there was no significant difference in the components. This was probably because the branch acts as the channel to gain the nutrient for leaf, at the same time 
considering the temporary "warehouse" (Gosz et al. 1973). Thus, the content of nutrient in leaf and branch appeared as "complementary" response.

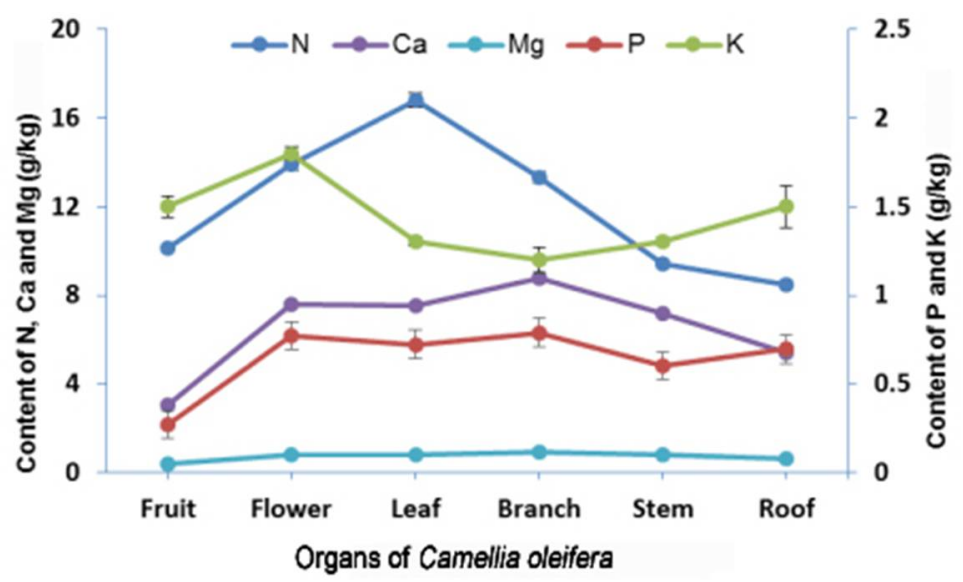

Fig. 1. Content of macroelements in different organs of Camellia oleifera.

The content of microelement in various organs of Camellia oleifera tree is presented in Fig. 2. It suggested that the content of $\mathrm{Mn}$ in Camellia oleifera was highest than the others, ranging approximately $145-881 \mathrm{mg} / \mathrm{kg}$. Correspondingly, the $\mathrm{Cd}$ was the lowest, ranging approximately $0.37-1.36 \mathrm{mg} / \mathrm{kg}$. Furthermore, the leaf contained significant amounts of microelement, but indistinctively to fruit, indicating the leaf was more suitable to be the feedstock for the production of fodder. The highest content of $\mathrm{Cu}$ was in the branch, which reached to $8.3 \mathrm{mg} / \mathrm{kg}$. Nevertheless, there was little difference in other organs of Camellia oleifera tree. Furthermore, the highest content of Fe was in the root that reached to $215.8 \mathrm{mg} / \mathrm{kg}$ and the flower only had $1.4 \mathrm{mg} / \mathrm{kg}$, indicating an obvious difference between organs. The branch and leaf contained the highest content of $\mathrm{Cd}, \mathrm{Pb}$ and $\mathrm{Mn}$, while the lowest level was observed in fruit.

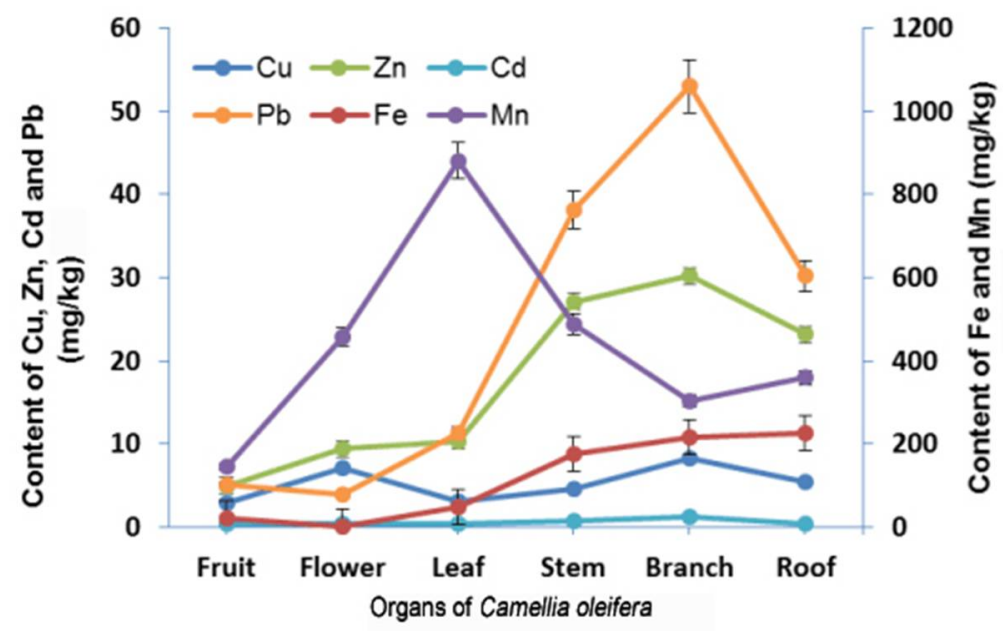

Fig. 2. Content of microelements in different organs of Camellia oleifera. 
The distribution of nutrient elements in the soil of OTF was regular, meanwhile there were some differences in the content of nutrient within various layers of soil. Some researchers (Liu et al. 2018) had illustrated that the $\mathrm{pH}$ of soil would be raised with the increase of soil depth. The value of $\mathrm{pH}$ recoded was 4.86 at $20-40 \mathrm{~cm}$ of soil depth, indicating the soil was acidic. Fig. 3 shows that the highest content of macroelement in the soil was $\mathrm{Ca}$, in $20-40 \mathrm{~cm}$. Furthermore, the content of $\mathrm{P}$ was not high in soil of OTF, mainly because it was easily immobilized by inorganic and organic molecules in soil, which might be one of the main inhibitors for plant growth (Schmidt 2015, Cui et al. 2017). Besides, in most of the soil in this country, lack of effective in soil was a common phenomenon, which demonstrated that the growing cycle of Camellia oleifera tree had a great demand for phosphorus from the soil (Richardson et al. 2009). Comparing the content of nitrogen in soil, the phosphorus is much lower, mainly due to the difference in origins of nitrogen and phosphorus.

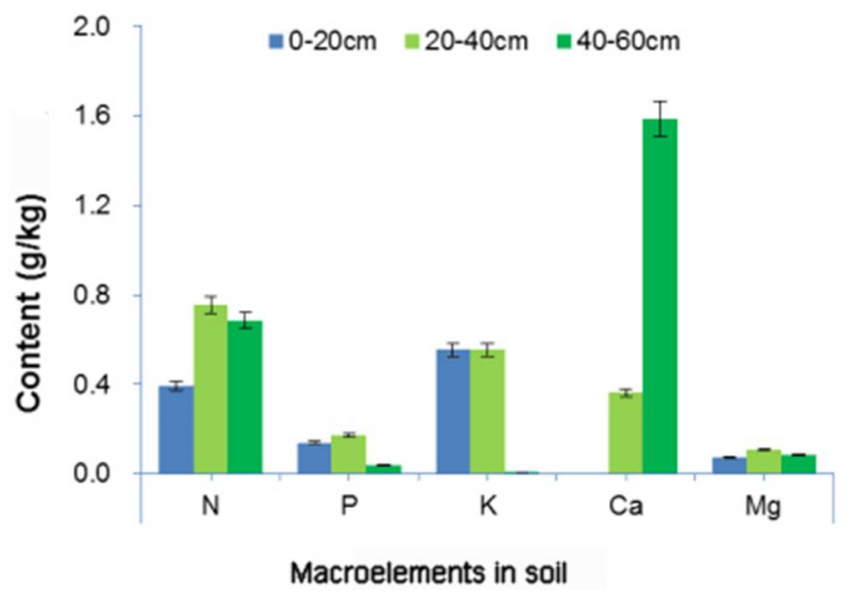

Fig. 3. Content of macroelements in soil.

The highest content of microelement in the soil was Fe, reached approximately 3926.4 $4237.1 \mathrm{mg} / \mathrm{kg}$, which was mainly distributed in $0-20 \mathrm{~cm}$ of soil depth (Fig. 4). This was probably because the research area was typical red soil containing higher amount of Fe. Moreover, the iron was not basically released at low $\mathrm{pH}$ in southern China. Fortunately, the OTF was nearly free of $\mathrm{Cd}$, which would conduce to the growth of Camellia oleifera tree and the innocuity of fruit.

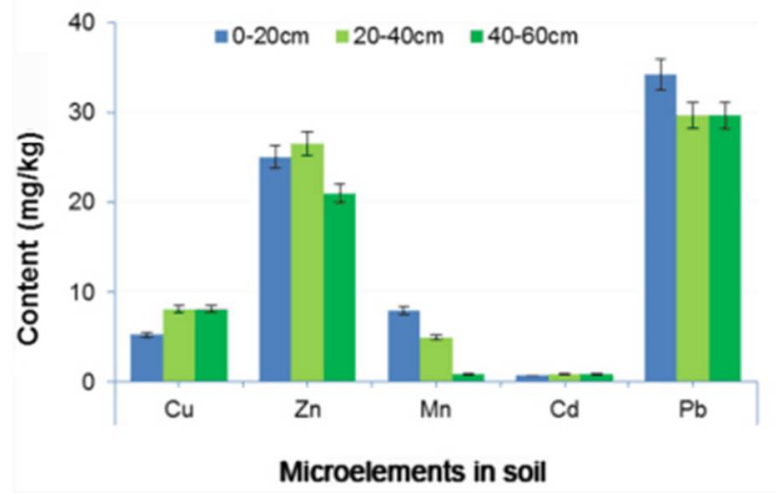

Fig. 4. Content of microelements in soil. 


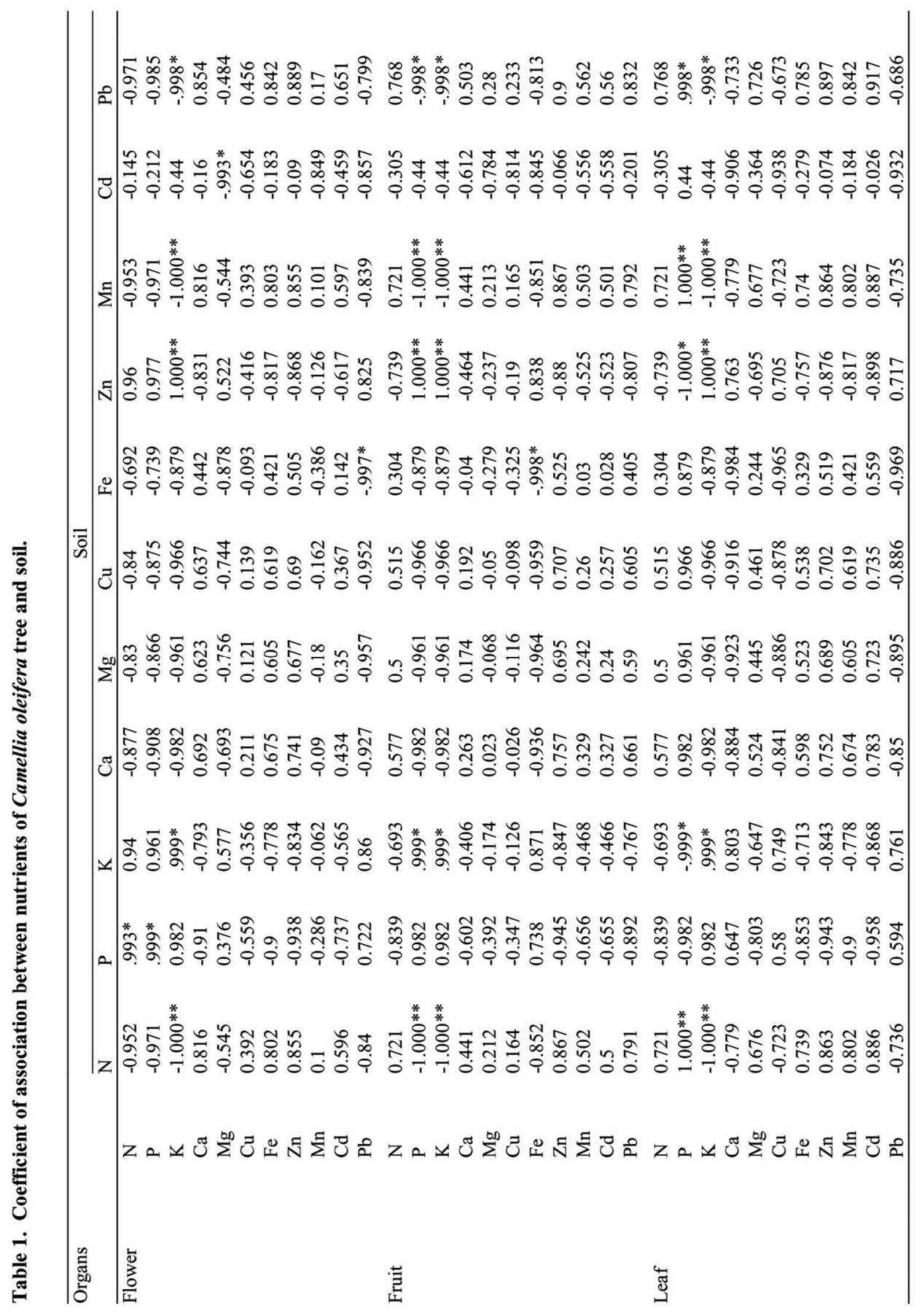


In the process of plant growth, there are five basic factors, including luminous energy, air, heat, water and nutrients. However, all these factors are associated with forest soil except luminous energy which suggested that forest soil is more suitable to plant growth. Thus, this study analyzed the correlation between the nutrient of Camellia oleifera tree with soil nutrient of OTF (Table 1, software of SPSS 17.0). The results indicated that there were different degrees of correlation between them (Table 1). The performance of significant or highly significant was 14 of soil with stem, 11 of soil with fruit, 10 of soil with roof, 10 of soil with leaf, 9 of soil with flower and 2 of soil with branch. Results further showed that 9 of pairing of correlation coefficients was significant between the nutrient of Camellia oleifera tree with $\mathrm{N}, \mathrm{Zn}, \mathrm{Mn}$ and $\mathrm{Pb}$ content of the soil; then, 8 of pairing was significant between the nutrient of Camellia oleifera tree with $\mathrm{K}, \mathrm{N}$, $\mathrm{Zn}, \mathrm{Mn}$ and $\mathrm{Pb}$ in the soil. Comparing the nutrient of Camellia oleifera tree and soil of OTF, furthermore, the $\mathrm{Mn}, \mathrm{N}$ and $\mathrm{Ca}$ were positively correlated. The elements of $\mathrm{Zn}$ and $\mathrm{Cd}$ were negatively correlated between plant and soil. Besides, the different organs of Camellia oleifera tree showed various selective specificities for elements in soil. Potassium was positively correlated, except for branch and root. Moreover, iron was negatively correlated, except for fruit and stem. This suggests that the Camellia oleifera tree had a great demand for potassium and iron, and the soil had a shortage of supply, which agreed with the findings of many researchers $\mathrm{Hu}$ et al. 2013). Coupling analysis, therefore, the results showed that there existed a complex interaction of elements in the soil and the effect of synergy or/and antagonism among of elements in plants. Consequently, the effect of interaction between elements should be fully considered for achieving the precise fertilization and further reduction in costs and increase in production. However, considering the effect of synergy or/and antagonism among the nutrients of plant and soil, it should be studied further to provide a technology support for better balanced fertilization and special fertilizer of Camellia oleifera tree.

\section{Acknowledgements}

This work was supported and funded by the Opening Project of National Engineering Research Center for Camellia oleifera (2015CY01), Hunan Province Chang-Zhu-Tan two oriented society construction service center project "to improve the quality of green heart, give play to the ecological function of countermeasures, and National Key R \& D Program of China(2017YFC0505506), Forestry Science and Technology Innovation Project in Hunan (XLK201970, HNGYL-2019-01, HNGYL-2020-01).

\section{References}

Chen JM, Yang XQ, Huang XM, Duan SH, Long C, Chen JK and Rong J 2017. Leaf transcriptome analysis of a subtropical evergreen broadleaf plant, wild oil-tea camellia (Camellia oleifera), revealing candidate genes for cold acclimation. BMC Genomics 18: 211-225.

Cui ZY, Xi RC, Deng XM and Xu DP 2017. A novel methodology for fertilization strategies: example of boron uptake and accumulation in Camellia oleifera. J. Trop. For. Sci. 29: 334-342.

Ding R, Deng XM, Ru C, Bao Y and Li YI 2012. Nutrient limiting factors in red soil from different parent rocks at oil-tea forest land of Guangdong province. Nonwood Forest Res. 30: 61-67.

Gao C, Yang R and Yuan DY 2017a. Characteristics of developmental differences between fertile and aborted ovules in Camellia oleifera. J. Am. Soc. Hortic. Sci. 142: 330-336.

Gao C, Yang R and Yuan D 2017b. Structural characteristics of the mature embryo sac of Camellia Oleifera. Nord. J. Bot. 36: 1-13.

Gao C, Yuan D, Yang Y, Wang B, Liu D and Zou F 2015. Pollen tube growth and double fertilization in Camellia oleifera. J. Am. Soc. Hortic. Sci. 140: 12-18. 
Gosz J, Likens G and Bormann F 1973. Nutrient release form decomposing leaf and branch litter in the hubbard brook forest, new hampsire. Ecol. Monogr. 43: 173-191.

Green and Jesse, 1931. Use of steam for kjeldahl distillation of nitrogen. Ind. Eng. Chem. Anal. Ed. 3: 160-161.

Hasegawa Y, Suzuki Y and Kawakubo S 2017. On-site determination of trace arsenic by reflection-absorption colorimetry of molybdenum blue collected on a membrane filter. Anal. Sci. 33: 859-862.

He F, Wang Y, Lu F, Zhang C and Zhu C 1996. Biomass accumulation and nutrient cycle in oiltea Camellia plantations. Scientia Silvae Sinicae 32: 403-410.

Hu D, Liu LY, Zhang WY, Wan XM and Guo XM 2013. Analysis on limiting factors of soil nutrient of Camellia oleifera forest in Jiangxi. Nonwood Forest Res. 31: 1-6.

Huang J, Ahrends A, He J, Gui H, Xu J and Mortimer P 2013. An evaluation of the factors influencing seed oil production in Camellia reticulata L. plants. Ind. Crop. Prod. 50: 797-802.

Jenden DJ, Taylor DB and Chem A 2002. Micro-kjeldahl distillation apparatus. Anal. Chem. 25: 685-685.

Lee CP and Yen GC 2006. Antioxidant activity and bioactive compounds of tea seed (Camellia Oleifera Abel.) oil. J. Agr. Food Chem. 54: 779-784.

Li H, Zhou G, Zhang H and Liu J 2011. Research progress on the health function of tea oil. J. Med. Plants Res. 5: 485-489.

Liu J, Wu L, Chen D, Yu Z and Wei C 2018. Development of a soil quality index for Camellia oleifera forestland yield under three different parent materials in southern China. Soil Till. Res. 176: 45-50.

Long QZ, Huang YH, Zhong HY, B. Danny R., P. Paul D. and R. Kevin, 2008. The quality and volatileprofile changes of camellia oil (Camellia oleifera Abel.) following bleaching. Eur. J. Lipid Sci. Tech. 110: $768-775$.

Pauli DJ. White W, Andradesanchez P, Conley MM, Heun J, Thorp KR, French AN, Hunsaker DJ, Carmosilva E and Wang G 2017. Investigation of the influence of leaf thickness on canopy reflectance and physiological traits in upland and pima cotton populations. Front. Plant Sci. 8: 1405-1449.

Richardson AE, Hocking PJ, Simpson RJ and George TS 2009. Plant mechanisms to optimise access to soil phosphorus. Crop. Pasture Sci. 60: 124-143.

Schmidt W 2015. From faith to fate: Ethylene signaling in morphogenic responses to P and Fe deficiency. J. Plant Nutr. Soil Sic. 164: 147-154.

Song XC, Tang J, Qin QY, Pan B and Cao JZ 2014. Mechanism of biomass accumulation and nutrient distribution in Camellia oleifera mature forest. J. Southern Agri. 45: 255-258.

Tang J, Qin ZY, Deng X J, Pan B, Nong BC and Song XC 2015. Study on leaf nutrient of Camellia oleifera in Guangxi by DRIS. J. Fujian Forest. Sci. Tech. 42: 11-16.

Tang L, Bayer E and Zhuang R 1993. Gewinnung, eigenschaften und verwendung des chinesischen teesamenöls. Fett/Lipid 95: 23-27.

Tomskii IS, Vishnetskaya MV, Vakhrushin PA and Tomskaya LA 2017. Oxidative desulfurization of straightrun diesel fraction on vanadium-molybdenum catalysts. Petrol. Chem. 57: 908-913.

Yao J, Deng Y, Du Z, Zhang M and Zhou X 2017. Analysis on planting densities of high yield and high efficiency for improved varieties cutting nursery of Camellia oleifera. Mol. Plant Breeding 15: 24562472.

Zhang LL, Wang YM, Wu DM, Xu M and Chen JH 2010. Comparisons of antioxidant activity and total phenolics of Camellia oleifera Abel. fruit hull from different regions of China. J. Med. Plants Res. 4: $1420-1426$. 